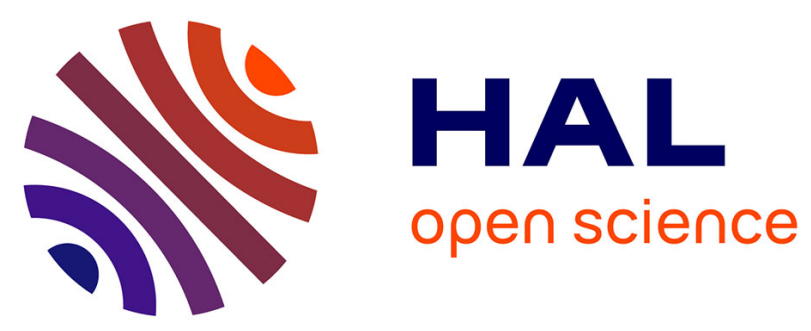

\title{
Scenarios for the Development and Use of Data Products Within the Value Chain of the Industrial Food Production
}

\author{
Volker Stich, Lennard Holst, Philipp Jussen, Dennis Schiemann
}

\section{- To cite this version:}

Volker Stich, Lennard Holst, Philipp Jussen, Dennis Schiemann. Scenarios for the Development and Use of Data Products Within the Value Chain of the Industrial Food Production. IFIP International Conference on Advances in Production Management Systems (APMS), Sep 2019, Austin, TX, United States. pp.294-302, 10.1007/978-3-030-29996-5_34 . hal-02460503

\section{HAL Id: hal-02460503 https://hal.inria.fr/hal-02460503}

Submitted on 30 Jan 2020

HAL is a multi-disciplinary open access archive for the deposit and dissemination of scientific research documents, whether they are published or not. The documents may come from teaching and research institutions in France or abroad, or from public or private research centers.
L'archive ouverte pluridisciplinaire HAL, est destinée au dépôt et à la diffusion de documents scientifiques de niveau recherche, publiés ou non, émanant des établissements d'enseignement et de recherche français ou étrangers, des laboratoires publics ou privés. 


\title{
Scenarios for the development and use of data products within the value chain of the industrial food production
}

\author{
Volker Stich $^{1}$, Lennard Holst ${ }^{1}$, Philipp Jussen ${ }^{1}$, Dennis Schiemann ${ }^{2}$ \\ ${ }^{1}$ Research Institute for Industrial Management (FIR) at RWTH Aachen, \\ Campus-Boulevard 55, 52074 Aachen \\ ${ }^{2}$ Lindt \& Sprüngli Germany GmbH, Süsterfeldstraße 130, 52072 Aachen
}

\begin{abstract}
The industrial food production is currently caught between the increasing demands of numerous stakeholders, economic profitability and the challenges of digitization. A solution to face these various challenges can be seen in the aggregation of data into higher-value, independent data products that can be offered and sold on a buyer's market. Large amounts of heterogeneous data are already available in the value chain of the industrial food production, e.g. throughout the data-driven harvesting of primary products, further processing by interconnected production facilities and the information-intensive product distribution to end consumers. However, the data is usually only evaluated and used locally for the optimization of internal processes or, at the most, within comprehensive partnerships. The purpose of this paper is to identify new revenue opportunities for current and future players in the industrial food production by using data as an independent economic good (data products). For this purpose, scenarios for the development and use of data products via Industrial Internet of Things platforms are developed for a food technical reference process, the industrial chocolate production and its value chain. On this basis, examples for different types of data products and their value propositions are derived. The results can not only serve food producers and relevant stakeholders but all industrial producers as an input for the future, yield-increasing orientation of their business models.
\end{abstract}

Keywords: Industrial food production, chocolate production, food value chain, data products via IIoT, scenario analysis, data economy

\section{Introduction}

The food industry plays a decisive financial and social role in the German economy with a turnover of 179.6 billion euro and more than 595.000 employees in 2017. It is the fourth largest economic sector in Germany and has a global significant influence on political and ecological relevant issues such as climate change, land usage, public health and environmental protection [1-3]. Alongside the entire value creation chain, industrial food producers face various internal and external challenges these days [4]. Global competition leads to increasing cost pressure while at the same time a large number of stakeholders exert influence on food production ecosystems. Manufacturers are forced 
to meet the increasing requirements of consumers and political regulations, demanding high quality and safety, sustainability, tracking and tracing of products, versatility and availability everywhere and at any time. Figure 1 shows the key stakeholders of industrial food production:

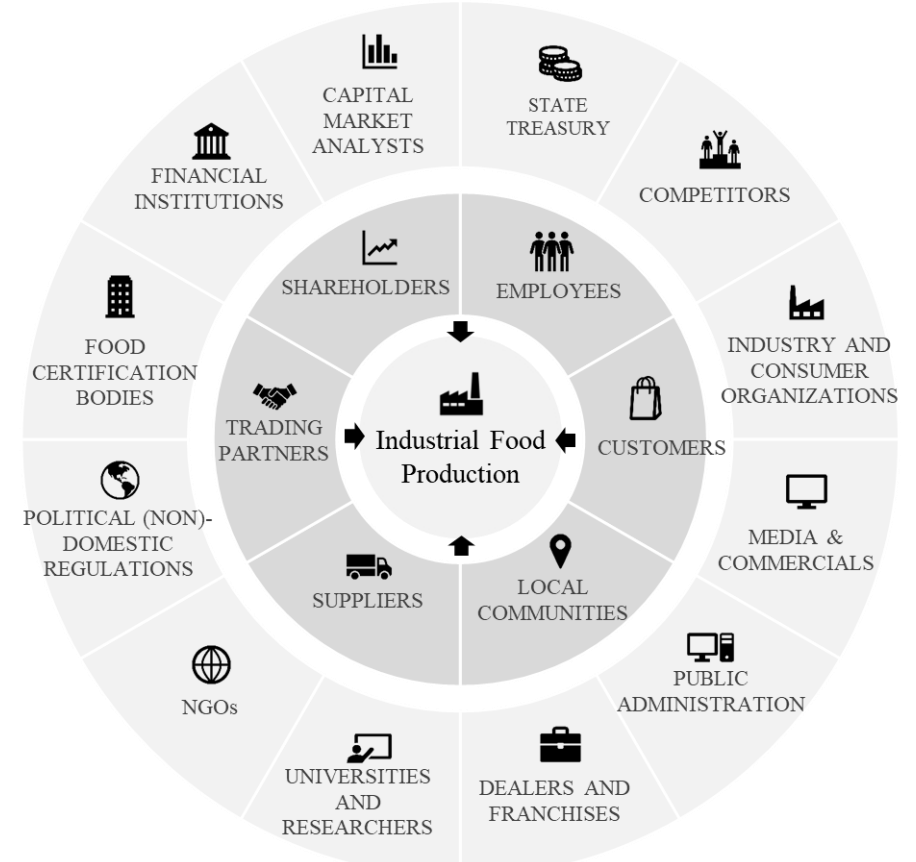

Figure 1: Mapping of stakeholders in the industrial food production ecosystem, based on [5]

In addition to the requirements of the relevant stakeholders, digitization is one of the greatest challenges and opportunities for industrial food producers. According to a recent survey by Bitkom Research on behalf of the Federation of the German Food Industry 70 percent of the industrial food producers consider digitization to be challenging meanwhile only 29 percent have their own dedicated digitization team. On the other hand, 98 percent of the companies expect increasing process efficiency as a result of digitization and 66 percent already use digital technologies [6].

Due to the increasing data base in the food industry, this paper addresses the chances of overcoming some of the numerous challenges by the development of data products (cf. Section 2). Through modern possibilities of mass data production, storage and processing via Industrial Internet of Things (IIoT) platforms, data can be transformed from a by-product to the actual core of the value proposition itself and can thus be traded as an independent asset (data product) via suitable marketplaces [7, 8]. IIoT platforms are technical systems which collect information about the use of physical things, e.g. production facilities, which are installed and used or operated over a distributed area and make this information available for further processing, e.g. for the development of apps $[8,9]$. For this purpose, it is necessary to consider the framework conditions for the development, trade and use of data products in a defined research area. Because food 
production is very broad and varied, the production of chocolate is used as the object of investigation i.e. as a reference process in this paper. The chocolate production combines a large number of comprehensive input factors and processes used across the board. While cocoa beans are subject to a manual harvesting process and thus generate little automated data input, other ingredients, such as sugar, can be obtained through a highly automated and data-driven beet harvest. The global supply processes, the further processing to cocoa mass and chocolate also generate large amounts of data. Further data is generated e.g. through sales and customer surveys. However, a comprehensive use of the data beyond the own ecosystem is currently not state of the art. Therefore, this paper presents research on data products and prognoses regarding the future of chocolate production in section 2. Additionally, a systematic scenario analysis is described (Section 3 ) and conducted (Section 4) to examine data products with regard to their opportunities on solving the presented challenges of industrial food production.

\section{State of Research}

Currently, there are no scenario descriptions for the use of data products in the chocolate production value chain in scientific and research literature. Therefore, data products (different types and a development process) and scenarios for future developments in chocolate production are examined separately. The results of this literature analysis show the research gap in the application of data product management within the chocolate production industry.

\subsection{Data products}

The significance of data as an actual value driver of a product or service increases rapidly. The change from data as a by-product or tool to the core of a value proposition to customers represents a new perspective especially for industrial production companies, which are used to develop, build and handle physical products. Several approaches can be found in literature to apply product management methods to the data perspective and in order to gain insights about data products and data product management [7, 10]. Within this paper, three different types of data products according to Tempich are examined [7]:

Type 1 - Data product as a service: Data can be used to generate direct sales, i.e. number of data $x$ price $=$ sales. Examples are stock exchange, address or weather data. Type 2 - Data enhanced product: Data can be used to enrich physical or virtual products. In this case, the change in sales of the physical product corresponds to the sales generated by the data. Examples are the Nike+ compatible products.

Type 3 - Data product as digital insight: Data usage to improve sales activities or quality, without involving external entities. This data product is only used internally (partnerships included) and does not generate direct revenue.

The development process of data products is described by Sands. According to her it should follow product management set ups with some major changes since e.g. the value of data products increases over the time correlating with the number of data and 
their users. The data component in product management adds an layer of complexity that should be tackled by emphasizing cross-functional collaboration, by evaluating data products in the long-term and by starting iteratively and simple when setting up a new digital business model [10].

\subsection{Future trends and scenarios for the chocolate production}

The future developments within chocolate production have been discussed in several interviews with leading managers of the chocolate manufacturer Lindt \& Sprüngli Germany. In addition to the technical and organizational challenges of digitization and data management within the production value chain, the issue of sustainable cocoa cultivation plays a very important role in future scenarios. A lot has been invested in the past to sustain and improve the conditions in the cocoa cultivating countries [11]. Further support for local farmers to increase the crop yield is expected to be needed, as currently the crop yield varies by a factor of 10 . Climatic conditions are another driver within future scenarios. Considering the current global warming speed, cocoa plants will no longer be able to be cultivated by the middle of the century because the soil will be too dry around the equator. Furthermore, the use of modern technologies plays a decisive role in the future of chocolate production. This includes new manufacturing technologies, the traceability of molds in production using tracking technology, an automatic inline quality control, automatic process engineering set ups at the production facilities, the use of IIoT platforms for comprehensive data analysis and cross-industrial networking as well as the prediction of the remaining lifetime for technical components. A stronger integration of the customer is also expected in the future. This is reflected in increasing customer requirements for information on the safe production of chocolate and in ordering batch sizes.

\section{Methodology}

At the beginning of the development of new products, such as data products, it is necessary to identify internal and external factors that have an influence on the company's ecosystem and the new products to be developed. A proven method for this is the scenario analysis, which is characterized by the design of alternative visions of the future. $[12,13]$. Various approaches of the scenario analysis are suggested in the literature, but most of them differ only in the accentuation of the content or the formal presentation, so that a general approach can be abstracted. Basically, the individual steps of the scenario analysis are to be determined separately for each situation and in dependence on the object of investigation. Due to the holistic approach, the focus is placed on the first five steps of the scenario analysis according to Reibnitz and Geschka [14, 15]:

\begin{tabular}{|c|c|c|c|c|}
\hline STEP 1 & STEP 2 & STEP 3 & STEP 4 & STEP 5 \\
\hline $\begin{array}{c}\text { Definition of the } \\
\text { Scenario field }\end{array}$ & $\begin{array}{c}\text { Scenario field } \\
\text { analysis/selection of } \\
\text { key factors }\end{array}$ & $\begin{array}{c}\text { Development of } \\
\text { alternative future } \\
\text { projections }\end{array}$ & $\begin{array}{c}\text { Creation and } \\
\text { analysis of } \\
\text { consistent scenarios }\end{array}$ & $\begin{array}{c}\text { Scenario assessment } \\
\text { / interpretation }\end{array}$ \\
\hline
\end{tabular}

Figure 2: The five steps of the scenario analysis research method, based on $[14,15]$ 
The first step is the definition of the scenario field, i.e. a description of the field of investigation (thematically, temporally, and territorially) whose future is to be mapped in the form of scenarios. In the second step, a large number of influencing factors on the object of investigation are systematically determined by environmental, environmental and influence analyses. Through literature analyses and workshops with experts, the influencing factors are weighted and key factors, i.e. factors with the most significant influence on the object of investigation, are selected. The third step involves the development of alternative future projections for the defined key factors. Three projection types are developed for this purpose: An optimistic, a neutral trend and a pessimistic type, based on literature research and expert interviews. In the fourth step, these three types of each key factor are evaluated with regard to their consistency with each other. The program ScenarioWizard is used to calculate consistent cross impact matrix to form various consistent scenario bundles. In the last step 5, the scenario bundles are finally described, interpreted and used to analyze implications on the initial question on how to develop and use data products within the industrial chocolate production as well as the food production in general.

\section{$4 \quad$ Results}

\subsection{Execution of the scenario analysis (Step 1 to 4)}

The research question on certain future scenarios for data products within the industrial food production value chain developed during the execution of the research project EVAREST (cf. Section 6). As the first step, this research question defined the scenario field, limited by the observation area of the chocolate production. In Step 2 the selection of key factors was conducted by a deep scenario field analysis. Therefore relevant literature and studies concerning data products were examined and current global and digitization developments in the chocolate industry were investigated with industrial experts. Using the theoretical, macroeconomic model of the PESTEL analysis, a long list of influencing factors was set up and factors were sorted into the categories political, economic, social, technological, ecological and legal aspects [16]. In expert workshops with Lindt \& Sprüngli Germany, 12 key factors were selected, described due to its current state and three future projections for each key factor, an optimistic, a trend and a pessimistic type, were developed (Step 3). In Step 4 the program ScenarioWizard was used to set up weighted cross impact matrices for the future projections. Thus, three consistent, global scenario alternatives were determined, that boast the highest degree of cross-linking between the different key factor projections.

\begin{tabular}{|c|c|c|c|}
\hline $\begin{array}{l}\text { A: Sustainability of cocoa } \\
\text { been cultivation }\end{array}$ & D: Industrie 4.0 & G: IIoT platforms & J: Data security \\
\hline B: Climatic change & E: Track \& Tracing & H: Digital business models & $\begin{array}{l}\text { K: Capabilities of data } \\
\text { product management }\end{array}$ \\
\hline C: Political restrictions & F: Individualized clients & I: Data market places & O: Education \\
\hline
\end{tabular}

Figure 3: 12 Selected key factors in the scenario field analysis 


\subsection{Scenario description and interpretation (Step 5)}

Based on the consistency analysis, the three global scenarios will be described from a future perspective. The different scenarios are illustrated in Figure 4 with regard to the development and monetarization possibilities of data products within each scenario alternative. Subsequently, conclusions on the use of data products are drawn.

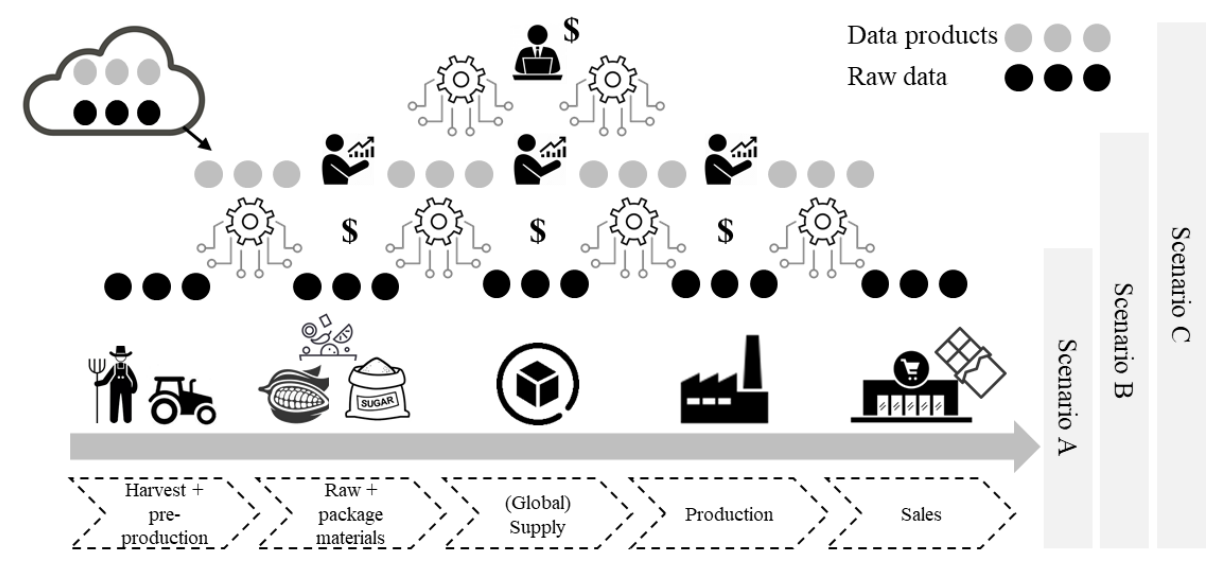

Figure 4: Development stages of data products, differing in the three global scenarios A to C

Scenario A can be considered a pessimistic extreme scenario. The digitization hype has led to a multitude of redundant systems and data sources. IIoT Platforms are available and in use to aggregate data, but there is no "Single Source of Truth". The collection of specific, valid data with time stamps fails. Data is only used to optimize the cocoa bean value chain. Due to insufficient broadband expansion this enormous quantity of data cannot be transmitted in real time. Data marketplaces are not profitable. There are no clear mechanisms for distributing the values generated from possible data products. Companies are too slow to establish comprehensive data science teams that can evaluate the heterogeneous data and combine domain knowledge of chocolate production with intelligent machine learning processes. In the countries where cocoa beans are grown, local political crises and global weather extremes also lead to crop failures that generally hamper the market. Furthermore, the large number of stakeholders makes a concrete orientation of data products, tailored to the various needs, impossible. In this scenario only data products of type 3 "data products as digital insights" are practicable. Scenario B can be considered a trend scenario. In particular, the secure use of IIoT platforms, also across manufacturers, enables a consistent data basis for smart services and aggregated data products. The data economy set up is ready for the trade of data products on suitable marketplaces with existing mechanisms for the fair distribution of the monetary value, added by the various data generators. A high level of traceability of the cocoa bean throughout all stages of the chocolate production value chain can be guaranteed. The further focus on the issue of sustainability in the cultivating areas leads to the increasing collecting of valid data about the harvest process. A practical example: The current demand of various stakeholders such as politicians, NGOs and consumers 
for $\mathrm{CO} 2$ reduction has increased further and can be addressed in the chocolate production by a type 2 data product. Each pack of chocolate contains a QR code that shows the exact manufacturing history including the overall $\mathrm{CO} 2$ emissions of a single chocolate product. A premium price can then be maintained or achieved for these products on the market. The optimistic extreme scenario $\mathrm{C}$ is based on the trend scenario. In this scenario a global data market is operated by data brokers. The use of digital technologies such as drones for crop monitoring and the distance measurement of plantations, as well as universally deployed sensors for soil data, leads to enormous amounts of data that can be traded on a real time capable stock market. In this scenario $C$ type 1 data products can be developed and aggregated, as a constant, real-time supply of valid data is guaranteed, while chocolate producers focus intensively on data value creation. Both the optimistic and trend scenario characterize an environment in which data products can be used for extensive monetization and not only complement the core business of chocolate production but also become a stand-alone digital business model.

\section{Conclusion and Outlook}

In this paper, key factors for the future development and use of data products within the food production industry were selected, using the chocolate production as a reference process. Three global scenario alternatives were developed, determined and illustrated. The validity of the scenario analysis as a strategic planning tool was ensured by the development of individual projections for each key factor and the establishment of cross-impact matrices by chocolate production experts. The further use of trend scenario B as a framework for a technical implementation of a suitable IIOT platform for the production and trading of data products is supported by the results of an internal Lindt Maturity Study on Industry 4.0. In the future, the key factor projections must be constantly evaluated for relevance in the context of changing framework conditions and stakeholder requirements in chocolate production. The food production specialists in the EVAREST consortium evaluated the general validity of the identified, projected and interpreted key factors regarding the transferability to other branches of the food industry. Figure 5 summarizes the research results on a comprehensive level, giving an estimation of the revenue increasing potential of the different data product types and classifying them into the different scenario set ups that were developed in this paper.

\begin{tabular}{lllll}
\hline Data product type & $\begin{array}{l}\text { General examples within the } \\
\text { industrial food production } \\
\text { value chain }\end{array}$ & Value propostion & $\begin{array}{l}\text { External } \\
\text { revenue } \\
\text { opportunities }\end{array}$ & $\begin{array}{l}\text { Scenarios with a } \\
\text { data product } \\
\text { ready set up }\end{array}$ \\
\hline $\begin{array}{l}\text { Type 1: } \\
\begin{array}{l}\text { Data product as a } \\
\text { service }\end{array}\end{array}$ & $\begin{array}{l}\text { Specific output data of } \\
\text { different processing stages }\end{array}$ & $\begin{array}{l}\text { High quantity of resilient } \\
\text { data to be sold on a real- } \\
\text { time capable data stock } \\
\text { market }\end{array}$ & ++ & (B), C \\
$\begin{array}{l}\text { Type 2: } \\
\text { Data enhanced product }\end{array}$ & $\begin{array}{l}\text { Data product as an add-on to } \\
\text { the food to ensure traceability }\end{array}$ & $\begin{array}{l}\text { Premium price for food that } \\
\text { can be tracked in detail }\end{array}$ & B, C \\
$\begin{array}{l}\text { Type 3: } \\
\begin{array}{l}\text { Data product as digital } \\
\text { insight }\end{array}\end{array}$ & $\begin{array}{l}\text { Exchange of raw material } \\
\text { quality data with suppliers and } \\
\text { cultivators }\end{array}$ & $\begin{array}{l}\text { Increasing product quality, } \\
\text { strengthening the internal } \\
\text { cohesion }\end{array}$ & A, B, C \\
\hline
\end{tabular}

Figure 5: Summary of the research results for the development and use of data products 


\section{Acknowledgements}

The research and development project EVAREST that forms the basis for this report is funded within the scope of the "Smart Data Economy" technology program run by the Federal Ministry for Economic Affairs and Energy and is managed by the DLR project management agency. The authors are responsible for the content of this publication.

\section{References}

1. Minhoff, C.: Jahresbericht 2017/2018 Bundesvereinigung der Deutschen Ernährungsindustrie e.V., Berlin (2018)

2. Berners-Lee, M., Kennelly, C., Watson, R., Hewitt, C.N.: Current global food production is sufficient to meet human nutritional needs in 2050 provided there is radical societal adaptation. Elem Sci Anth (2018). doi: 10.1525/elementa.310

3. United Nations: Sustainable Development Goals. https://www.un.org/sustainabledevelopment/sustainable-development-goals/ (2015). Accessed 28.03.19

4. Beulens, A.J.M., Broens, D.-F., Folstar, P., Hofstede, G.J.: Food safety and transparency in food chains and networks Relationships and challenges. Food Control (2005). doi: 10.1016/j.foodcont.2003.10.010

5. The Orlen Group: Orlen Group's stakeholder map. https://raportzintegrowany2015.orlen.pl/en/the-orlen-group-and-its-environment/the-orlen-group/ourstakeholders.html (2015). Accessed 29.03.19

6. Bitkom Research: Ernährung 4.0 - Digitalisierung bringt Transparenz für Industrie und Verbraucher. https://www.bve-online.de/veranstaltungen/konferenzen/unternehmertag-2019/interviews-ut-2019/beitrag-bitkom-studie (2019). Accessed 10.04.19

7. Tempich, C.: Inovex GmbH - Datenprodukte erklärt! https://www.inovex.de/blog/datenprodukte-erklaert/ (2017). Accessed 28.03.19

8. Dorst et al.: Digitale Geschäftsmodelle für die Industrie 4.0 (2019)

9. Gubbi, J., Buyya, R., Marusic, S., Palaniswami, M.: Internet of Things (IoT): A vision, architectural elements, and future directions. Future Generation Computer Systems (2013). doi: 10.1016/j.future.2013.01.010

10. Sands, E.: How to build great data products. https://hbr.org/2018/10/how-tobuild-great-data-products (2018). Accessed 28.03.19

11. Lindt \& Sprüngli AG: Sustainability Report 2017 (2017)

12. Eversheim, W.: Innovationsmanagement für technische Produkte. VDI-Buch. Springer, Berlin, Heidelberg (2003)

13. Hassani, B.K.: Scenario analysis in risk management. Theory and practice in finance. Springer (2016)

14. Reibnitz, U.: Szenario-Technik. Instrumente für die unternehmerische und persönliche Erfolgsplanung, 2nd edn. Gabler Verlag, Wiesbaden, s.l. (1992)

15. Geschka, H., Hammer, R.: Die Szenario-Technik in der strategischen Unternehmensplanung. In: Hahn, D., Taylor, B. (eds.) Strategische Unternehmungsplanung, pp. 311-336. Physica-Verlag HD, Heidelberg (1990)

16. Yüksel, I.: Developing a Multi-Criteria Decision Making Model for PESTEL Analysis. IJBM (2012). doi: 10.5539/ijbm.v7n24p52 